\title{
Representativeness of Participants in Heart Failure E-Health Trials: A Report From the E- Vita HF Study
}

Kim P. Wagenaar, Niaz Hakim, Berna D. L. Broekhuizen, Tiny Jaarsma, Frans H. Rutten and Arno W. Hoes

Journal Article

Tweet

N.B.: When citing this work, cite the original article.

Original Publication:

Kim P. Wagenaar, Niaz Hakim, Berna D. L. Broekhuizen, Tiny Jaarsma, Frans H. Rutten and Arno W. Hoes, Representativeness of Participants in Heart Failure E-Health Trials: A Report From the E-Vita HF Study, Journal of Cardiac Failure, 2017. 23(1), pp.88-89.

http://dx.doi.org/10.1016/j.cardfail.2016.08.006

Copyright: Elsevier

http://www.elsevier.com/

Postprint available at: Linköping University Electronic Press

http://urn.kb.se/resolve?urn=urn:nbn:se:liu:diva-134495

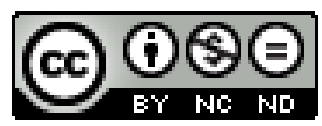


Representativeness of participants in heart failure e-health trials: a report from the e-Vita heart failure study

Authors: Kim P Wagenaar ${ }^{1}$, Niaz Hakim ${ }^{1}$, Berna D L Broekhuizen ${ }^{1}$, Tiny Jaarsma², Frans H Rutten ${ }^{1}$, and Arno W Hoes ${ }^{1}$

${ }^{1}$ Julius Center for Health Sciences and Primary care, University Medical Center Utrecht, The Netherlands, ${ }^{2}$ Linköping University, Department of Social and Welfare Studies, Sweden.

Corresponding author: Kim P Wagenaar, Julius Center for Health Sciences and Primary care, Universiteitsweg 100, 3584 CG Utrecht, The Netherlands, Phone: 0031(0)887568167, E-mail: K.Wagenaar-2@umcutrecht.nl 


\section{Research letter}

Well-designed and properly executed randomized controlled trials (RCTs) provide the strongest evidence on the effects of interventions. However, eligibility criteria and the willingness to participate may result in differences between participants and non-participants. When participants differ considerably from non-participants, the participants will not be representative for the domain of study. As a consequence, the results of the trial may not be generalizable to that domain of patients. (1) However, this will only be the case if the characteristics (e.g. age) in which the groups differ, modify the effect of the intervention (e.g. that the effect is larger or smaller in older or younger patients). (2) Such 'effect modifiers' may differ per intervention. Selectivity of participants of RCTs in general is well known but representativeness of heart failure (HF) patients in e-health trials is lacking. Insight in representativeness in e-health is pivotal as the number of trials in this area increases. They might even be more sensitive to selectivity then device and drug trials in $\mathrm{HF}$, as they require active participation and possible technical 'savviness'. We aimed to compare characteristics of participants with non-participants in the e-Vita HF study that evaluates e-health in patients with HF and to compare characteristics of e-Vita HF participants with participants of previous ehealth randomized studies in HF.

We used data from the Dutch multicenter e-Vita HF study, a randomized trial on the effectiveness of two e-health tools in patients with HF. (3) Eligibility criteria are reported elsewhere. (3) In total, 405 patients consented to participate. A random sample of nonparticipants $(n=402)$ were taken as the comparison group. Demographic and disease-specific characteristics of the participants and the non-participants were collected at baseline. In addition, we collected potential effect modifiers for e-health interventions: age, comorbidities, and socio- 
economic status (SES). (4) To define SES, the 4 digits of the Dutch postal codes were linked to a SES according to the Netherlands Institute for Social research database (SCP). (5) The SES was categorized for the present analysis as: $<0=$ low SES, $0=$ middle SES, $>0=$ high SES. Participants signed an informed consent, and the data of the non-participants was stored and analyzed anonymously. This strategy was approved by the Medical Ethical Committee of the University Medical Center Utrecht. Information about participants of previously performed ehealth studies was retrieved from a recently published Cochrane review. (6)

Table 1 shows characteristics of participants and non-participants. Participants were younger (mean age 66.7 vs. 73.4 years), more often male ( $75 \%$ vs. $58 \%$ ), and had fewer comorbidities. After adjustment for age anemia and angina pectoris were no longer significantly different, and SES became significantly higher in participants. From the Cochrane review we retrieved information on participants (data on non-participants was not presented) of 18 studies evaluating telemonitoring interventions, published between 2001 and 2014. The mean age was 68 years (range 54 to 78 years), 73\% (range 35 to $85 \%$ ) were men, 30\% (4 to 43\%) with diabetes and $43 \%$ (15 to $67 \%)$ with hypertension. 
Table 1. Demographic and disease-specific characteristics of the participants and non-participants in the e-health e-Vita HF trial

\begin{tabular}{|c|c|c|c|c|}
\hline \multirow[b]{2}{*}{ Demographics } & \multirow{2}{*}{$\begin{array}{l}\text { Participants(N=405) } \\
\%\end{array}$} & \multicolumn{3}{|l|}{$\begin{array}{l}\text { Non- } \\
\text { participants } \\
(\mathrm{N}=402)\end{array}$} \\
\hline & & $\%$ & $\begin{array}{l}\text { P- } \\
\text { valueq }\end{array}$ & $\begin{array}{l}\text { P-value } \\
\text { (adjusted } \\
\text { for age)§ }\end{array}$ \\
\hline Female sex & 25.2 & 42.3 & $<0.001$ & $<0.001$ \\
\hline $\begin{array}{l}\text { Mean age in } \\
\text { years (SD) }\end{array}$ & 66.7 (10.8) & $73.4(11.1)$ & $<0.001$ & NA \\
\hline \multicolumn{5}{|l|}{ SES*† } \\
\hline Low & 16.5 & 19.9 & 0.34 & 0.02 \\
\hline Middle & 38.0 & 39.3 & & \\
\hline High & 44.9 & 40.8 & & \\
\hline \multicolumn{5}{|l|}{ Comorbidities } \\
\hline $\begin{array}{l}\text { Angina } \\
\text { pectoris }\end{array}$ & 17.8 & 24.6 & 0.02 & 0.15 \\
\hline Prior MI & 42.2 & 41.0 & 0.73 & 0.42 \\
\hline Hypertension & 44.0 & 62.2 & $<0.001$ & $<0.001$ \\
\hline Hyperlipidemia & 40.0 & 38.3 & 0.62 & 0.57 \\
\hline Anaemia & 15.1 & 20.9 & 0.03 & 0.79 \\
\hline Diabetes & 25.2 & 30.1 & 0.12 & 0.25 \\
\hline $\begin{array}{l}\text { Renal } \\
\text { insufficiency } ¥\end{array}$ & 15.6 & 40.3 & $<0.001$ & $<0.001$ \\
\hline $\begin{array}{l}\text { COPD / } \\
\text { Asthma }\end{array}$ & 25.7 & 21.4 & 0.15 & 0.07 \\
\hline Cancer & 18.0 & 21.4 & 0.23 & 0.62 \\
\hline Sleep disorders & 9.6 & 8.7 & 0.65 & 0.70 \\
\hline
\end{tabular}

*SES=socio-economic status, $\uparrow 0.5 \%$ missing among participants, $\ddagger \mathrm{MI}=$ myocardial infarction, ¥renal insufficiency = patients $<65$ years, creatinine clearance $<45 \mathrm{ml} / \mathrm{min} ; \geq 65$ years, creatinine clearance $<30$ $\mathrm{ml} / \mathrm{min}$, ๆP-value calculated with chi-square test and T-test, §P-value calculated with multiple linear or (ordinal) logistic regression analysis. 
The e-Vita HF trial participants were similar to the participants of previous e-health studies. This is the first study on representativeness of HF participants in an e-health RCT. In line with RCTs evaluating pharmaceutical interventions in chronic HF patients, participants in the e-Vita HF study were younger, more often male and had fewer comorbidities than nonparticipants. (7) However, importantly, the modifying effect of these characteristics may vary between pharmaceutical and e-health interventions. It has been suggested that gender may modify the effect of drug interventions in HF because women have more often HF with preserved ejection fraction, are older and have more comorbidities. (8) Such gender-related differences that may affect the outcomes have not yet been suggested in e-health interventions. (4) The SES between participants and non-participants differed after adjustment for age. This confirms previous studies showing an association between SES and the use of internet in elderly. $(9,10)$ A limitation of this study is that marital status and interest in new technical items as potential effect modifiers were not included. (9) Further research should address to what extent age, comorbidity and other patient characteristics actually modify the effect of e-health tools in HF. This requires detailed characteristics of non-participants to be reported in future trials and individual patient data analysis to assess subgroup effects (identify effect modifiers).

In conclusion, participants differ from non-participants in HF e-health studies.

Differences between participating and non-participating HF patients should be taken into account in the interpretation of research findings and e-health trials should report patient's characteristics of non-participants. 


\section{Conflicts of interest}

None declared.

\section{Funding}

This study has been funded by the Foundation “Care Within Reach” (In Dutch: Stichting Zorg Binnen Bereik). 


\section{References}

1. Baker TB, Gustafson DH, Shaw B, Hawkins R, Pingree S, Roberts L, et al. Relevance of CONSORT reporting criteria for research on eHealth interventions. Patient education and counseling. 2010;81 Suppl:S77-86.

2. Van Den Akker EH, Rovers MM, Van Staaij BK, Hoes AW, Schilder AG.

Representativeness of trial populations: an example from a trial of adenotonsillectomy in children. Acta oto-laryngologica. 2003;123(2):297-301.

3. Wagenaar KP, Broekhuizen BD, Dickstein K, Jaarsma T, Hoes AW, Rutten FH. Effectiveness of an interactive platform, and the ESC/HFA heartfailurematters.org website in patients with heart failure: design of the multicentre randomized e-Vita heart failure trial. European journal of heart failure. 2015;17(12):1310-6.

4. Neter E, Brainin E. eHealth literacy: extending the digital divide to the realm of health information. Journal of medical Internet research. 2012;14(1):e19.

5. The Netherlands Institute for Social research: The Netherlands Institute for Social research; 2015 [cited 2015 March 5]. Available from:

http://www.scp.nl/Onderzoek/Lopend_onderzoek/A_Z_alle_lopende_onderzoeken/Statusscores.

6. Inglis SC, Clark RA, Dierckx R, Prieto-Merino D, Cleland JGF. Structured telephone support or non-invasive telemonitoring for patients with heart failure. Cochrane Db Syst Rev. 2015(10).

7. Kennedy-Martin T, Curtis S, Faries D, Robinson S, Johnston J. A literature review on the representativeness of randomized controlled trial samples and implications for the external validity of trial results. Trials. 2015;16:495.

8. Reddy YN, Borlaug BA. Heart Failure With Preserved Ejection Fraction. Current problems in cardiology. 2016;41(4):145-88.

9. Friemel TN. The digital divide has grown old: Determinants of a digital divide among seniors. New Media Soc. 2016;18(2):313-31.

10. Levy H, Janke AT, Langa KM. Health literacy and the digital divide among older Americans. Journal of general internal medicine. 2015;30(3):284-9. 